sacrum, nor any distinction between the cervical, dorsal, and lumbar vertebræ. The amount of movement between each pair of vertebræ is extremely small, but, when taken together, is considerable. The ribs are always free at their inferior extremities. The floor of the cranium is nearly flat, and the vertical height of its cavity diminishes gradually in front, so that it remains spacious between the eyes; the presphenoidal region is not elevated, as in the lizards. The bones constituting the brain-case are firmly united together and ossified. The nasal section is less completely ossified. The premaxillaries are usually represented by a single small bone, connected to the maxillæ only by fibrous tissue. The palatine bones never unite with the vomer or with the base of the skull, but are usually united with the maxilla by transverse bones, and by the pterygoids with the quadrate bone. The rami of the mandible are only united by ligamentous fibres, which are often very lax. In some respects, the skull of the snake departs from that of all other vertebrates; thus the sphenoid passes in front of the sella turcica into a great rostrum, which extends forwards to the ethmoid region. The postfrontals are usually well developed; and there are large membrane bones in front of the orbit which lie on the cartilaginous nasal chambers. Snakes are divided into two groups - the non-venomous and the venomous snakes. Of the former, the python is a good example; and, of the latter, the rattlesnake. In the former, the maxillaries give attachment to a long series of recurved teeth. The squamosal bones are long, and adhere to the skull; and to their posterior ends the quadrate bones are attached. The rami of the mandible are loosely connected, so as to admit of being widely separated. The squamosal and quadrate bones form a kind of jointed lever, which, when straightened, causes separation of the mandibles from the base of the skull. Those arrangements in conjunction allow immense distension of the throat, and enable the animal to swallow large prey. In the rattlesnakes, the premaxilla are small and toothless; the maxillæ are short. When the mouth is shut, the axis of the quadrate bone is inclined downwards and backwards. The poison-fangs, which are attached to the palatine face of the maxillæ, are directed backwards, and lie concealed along the roof of the mouth. When the animal opens its mouth for the purpose of striking its prey, the digastric muscle pulls up the angle of the mandible and at the same time pushes the distal end of the quadrate bone forwards. This causes the pterygoid to be pushed forward, and also causes the bending of the palatine joint of that bone, and the partial rotation of the maxillary bone upon its lacrymal joint, the hinder edge of the maxilla being thrust forwards and downwards. As a result of this motion, the dentary surface of the maxilla looks downwards and a little forwards, and the fangs are brought into a vertical position. The animal now strikes its prey; and, by the contraction of a muscle extending over part of the poisun-gland, the contents of the latter are forced out through the canal in the fang into the wound. The fang being withdrawn, the movements of the various parts take place in the reverse order, and the parts return to their former condition.

Kensington.-Dr. Dudfield's monthly reports for $\mathrm{I} 880$, now col lected together in one volume, need no commendation at our hands. Nor is it necessary to do more than refer to the special report which he has presented to his Vestry on the compulsory notification of infectious diseases, because the facts he gives have already appeared in these columns. It may be well, however, in anticipation of the detailed annual report which the Health Officer will doubtless submit later on, to give a brief summary of the vital statistics of Kensington for last year. Dr. Dudfield says that the state of the public health in 1880 was, in all respects save one, more favourable than 1879 , and considerably better than the decennial average. It is hardly satisfactory, however, to read that this exception was the excessive prevalence of certain diseases of the zymotic class, though it is true the deaths from the principal diseases of this class were below the average. The birth-rate (29 per $1,000)$ was considerably below that obtaining for the metropolis generally; and the same remark applies to the death-rate, which was 18 per 1,000. The deaths of young children were equal to 42 per cent. of the total deaths, and 26.3 per cent. of registered births. Zymotic diseases caused 467 deaths, against 339,573 , and 547 in the three preceding years. Scarlatina was the most serious epidemic of the year, 466 cases (with 105 deaths) being recorded. This, however, by no means represents the actual amount of prevalence in the district: for many of the cases, especially in the north part of the district, were concealed. Of small-pox, there were 50 cases and II deaths, eight of which occurred in the Fulham Hospital. Diseases of the respiratory organs were fatal to 880 persons, or about 200 less than in 1879 . Heart-diseases were fatal in 144 cases - a number below the average. The violent deaths were 60 ; and 172 deaths formed the subject of inquiry by the coroner. The number of uncertified deaths was 27 , the majority of these being infants, whose deaths were registered on the information of midwives.

\section{ON THE AFFECTION OF BONES AND JOINTS IN LOCOMOTOR ATAXY, AND ITS ASSOCIATION WITH GASTRIC CRISES.*}

By THOMAS BUZZARD, M.D., F.R.C.P., Physician to the National Hospital for the Paralysed and Epileptic.

IN February 1880, I submitted tot he Pathological Society of Londont three patients suffering from osseous and articular lesions in the course of tabes dorsalis; and I referred to another case published by me in the Lancet, August 22nd, 1874. In one of these four cases, the right hip-joint was completely disorganised (the head and neck of the femur having entirely disappeared). In a second, there was disorganisation of the left knee-joint, with enormous swelling of the limb. In a third, a female, there had been spontaneous fracture of both femora in succession through their necks, with atrophic changes of the bones. The fourth case, also a female, was one in which there was complete disorganisation of both knee-joints, which had taken place without pain, and some recent swelling and crepitation of the right shoulder-joint. These patients were all well-marked examples of locomotor ataxy. 'Two of them-the two female patients shown to the Pathological Society - suffered from most characteristic attacks of the crises gastriques of Charcot; attacks in which there is pain in the stomach and chest, with spontaneous retching and vomiting, occurring at irregular intervals, and leaving the patient free from gastric derangement between the seizures.

I was much struck by the fact of two ataxic patients, the subject of osseous changes, being likewise affected with gastric crises. Both conditions are very exceptional in tabes; and their coincidence, therefore, in two cases, suggested to me the idea of investigating whether there were not grounds for believing the association to be something more than an accidental one. I found that, in a certain list of fifty-six cases of tabes in my own practice, I had only met with gastric symptoms eight times, and in only four of these could the attacks be called typical gastric crises. On the other hand, when I came to search recorded examples of osseous and articular changes of this kind in the French journals, it appeared to me that gastric crises were extraordinarily frequent in cases of arthropathy. They occurred in the only case of spontaneous fracture in a tabetic patient which Vulpian had witnessed; and, in a list of sixteen other French cases of arthropathy, gastric crises were present in no fewer than six. In the discussion which followed the reading of my paper, the President (Mr. Hutchinson) related a case of arthropathy with gastric crises; and Dr. Sturge referred to another in which the same association was to be found. Since that date, four more cases of tabetic arthropathy have come under my observation, and I propose to read notes of them today. It will be seen that in three out of four there is again the association of typical gastric crises with affection of the joints or bones.

As a matter of statistics, it now comes to this : out of seventy cases of tabes which have occurred under my own observatior, I have found gastric symptoms in twelve; but in only eight of these did they amount to the characteristic crises gastriques of Charcot. On the other hand, out of thirty cases of affections of bones and joints in tabes that $I$ have collected from various sources(including my own), no fewer than fourteen, or nearly half, were affected with typical crises gastriques. I have no doubt that there are many more cases published; but I have not had leisure to seek for them. Whilst searching the French journals for data upon this point, I found that Professor Ball, in his papers upon the subject published in the Gazette des Hôpitaux (1868.69), refers to the frequency of "visceral lesions" in the cases of arthropathy which he relates.

The following cases are now brought forward for the first time.

CASE 1.-J. R. P., aged 60, was admitted into the National Hospital for the Paralysed and Epileptic on July 2nd, I880, under my care. The following notes were taken by Dr. Beevor, resident medical officer. For fourteen years he had suffered from characteristic lightning-pains in the legs, and for two years his gait had been ataxic. Cutaneous sensibility was greatly impaired in his feet, and a pin-prick was felt only after a delay of two or three seconds. Patellar tendon-reflex was absent.

* Read in the Section of Pathology at the Annual Meeting of the British Medical Association in Cambridge, August 880 .

$\dagger$ Transactions of the Pathological Society of London, vol. xxxi, p. 193. 
The pupils were small (No. o Hutchinson); they contracted during accommodation, but not to light. There was delay with the bladder.

Between July and November I879, the left lower extremity became greatly swollen from above the knee to the ankle, without any pain. Last February, the swelling went down, and the knee-joint was found to be loose, as it is now. The joint remained enlarged ; it tapered upwards, and was rounded abruptly below. Its circumference was fifteen inches and a half, against thirteen inches and a half, the measurement of the right knee. The joint was semi-elastic on palpation; and the capsule appeared to be much thickened, especially in front. Grating was felt when the patella, which floated, was rubbed upon the end of the femur, and when the tibia was rubbed against the femur. The joint was very loose, the tibia being capable of abduction so as to form an angle of $150^{\circ}$ with the femur. The

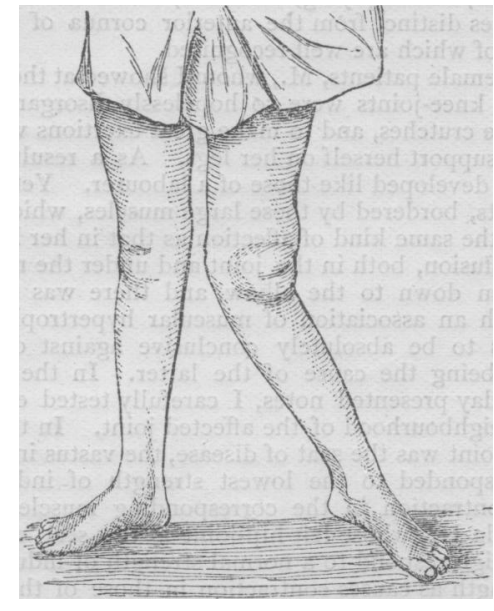

Case I.

left thigh lying flat on the bed, the tibia could be over-extended, so that the heel could be elevated nine inches; and it could be rotated freely. The left vastus internus muscle contracted at its motor point to the lowest strength of induced current required to cause contraction of the right vastus internus.

CASE 11.-Henry H., aged 62, was an inmate of the Kensington Workhouse, for the opportunity of examining whom I am indebted to the kindness of Dr. Whitmore, resident medical superintendent. About ten years ago, the patient suffered from epigastric pain, retching, and vomiting, which lasted for nine months, not always equally severe, but so bad that he never left his room, and but rarely his bed. The retching occurred independently of any food being swallowed, and the pain was so severe that he rolled about. His symptoms gradually subsided and he returned to his employment (cab-driving), but was still subject at times to return of pain and retching. At the end of a year, he had another prolonged attack, lasting on this occasion three months; and he has had in all half-a-dozen attacks of the same kind since the first. They would last about six or seven weeks, during which he had been obliged to keep his bed. For three or four years he had been liable to sharp momentary pains-in the legs at first, and eventually in all parts of the body; an attack of these pains lasting from twelve to twenty-four hours. At the present time, he scarcely ever goes a day without them. He is a spare, not unhealthy-looking man, who, if he takes his time, can walk ten miles. ( $\mathrm{He}$ is now employed as a messenger.) There is no ataxy; but he is lame in the left leg from localised paralysis of the tibialis anticus group of muscles, which give no response to electrical currents. Electrical currents cause no sense of pain, though he recognises the very lightest touch. Patellar tendonreflex is absent. The quadriceps extensor muscles act normally to the induced current. The skin-reflex of his soles is slightly in excess. His pupils do not contract to light, nor during accommodation. The left shoulder-joint is enlarged, and apparently contains fluid. It is abnormally movable; and there is much crepitus when the humerus is rotated, which it can be with quite unnatural freedom. The head of the bone has apparently disappeared; and the limb can be pushed upwards so that the left upper arm becomes more than an inch shorter than the right. The shoulder began to swell nearly three years ago, the swelling extending down the whole upper arm to the elbow, where it pointed and matter was discharged. At the same time, he says, the left side of his chest was also swollen.

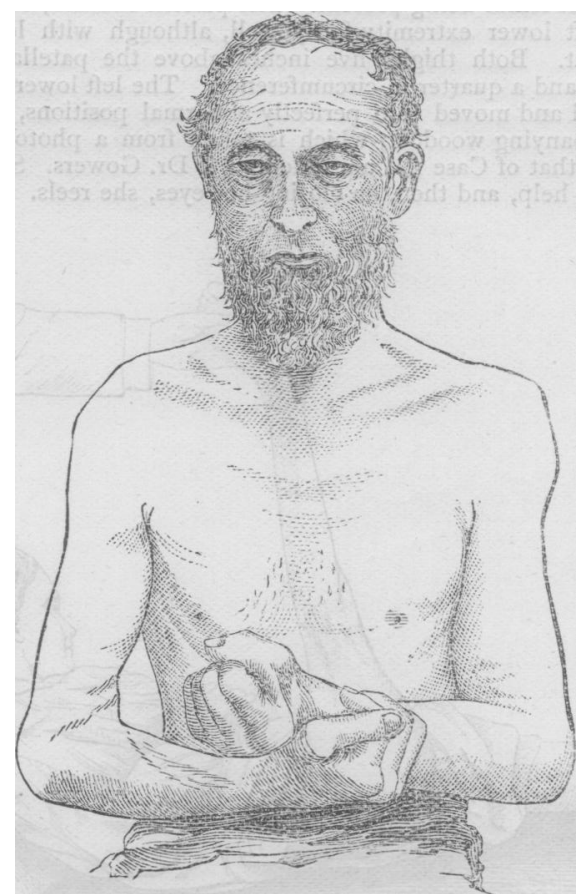

Case Ir.

CASE III.-Matilda H., aged 50, was a patient in the National Hospital, under the care of my colleague Dr. Radcliffe, to whose courtesy I am indebted for the opportunity of including the case. Notes were taken by Dr. Beevor. Ten years ago, she had a slight attack of left hemiplegia, from which she recovered entirely in a week. For fifteen years she has suffered from so-called "rheumatic pains" in the arms and legs, and for the last five years she has been ataxic. Eighteen months ago, her left hip-joint gave way with a snap as she was stooping down, but without any pain; and she found she could not stand on the left leg. Directly afterwards, she noticed a swelling in the left groin; and, a few months later, the left leg was noticed to be shorter than the right; and it has continued, she says, to grow shorter.

Momentary shooting-pains have existed for two years. They come on suddenly, and she feels as though her joints were being "screwed into". They have been apt to attack the outer malleoli, the legs, and the hams; but they have never occurred in either of her hip-joints. They are very sharp, "like flashes of lightning", and make her cry out. Cutaneous sensibility is somewhat impaired in the legs, and there is a little delay in appreciating pricks with a pin. There is marked hyperalgesia to hot metal in the legs; but there is a delay of three seconds before she can feel the heat, which is then described as intolerable. Patellar tendon-reflex is absent. The vastus internus muscle of each thigh reacts normally to induced currents. The pupils are equal (size of No. 3 Hutchinson). They contract during accommodation, but not to light.

For seventeen years, the patient has been subject to attacks of vomiting, which at first would occur about once in a year, and last from ten to twelve days. For the last two years, these attacks have been much more frequent, and she will have one (lasting a week or more) every three or four weeks. There is nausea, vomiting, and cramp-like pain in the epigastrium, which makes her "twist about". She brings up a great deal of flatus, and there is much empty retching. The presence or absence of food in the stomach appears to have no influence on the vomiting. Her left lower extremity is shorter than the right, measuring thirty-one inches from the anterior superior iliac spine to the inner malleolus, against thirty-two inches and a half, the measurement on the right side. The left trochanter major is four inches below the anterior superior iliac spine, and half an inch outside a line drawn vertically downwards from that spine. The right trochanter, on the 
other hand, is four inches outside a corresponding line. The right femur rotates in an arc of a circle of which the bead of the bone is the centre, whereas the left rotates around its own shaft as a centre. The left leg can be drawn down nearly two inches. There is no sign of the head of the left femur being present. The patient can flex, extend, and rotate her left lower extremity fairly well, although with less power than the right. Both thighs, five inches above the patella, measure fifteen inches and a quarter in circumference. The left lower extremity can be rotated and moved into perfectly abnormal positions, as shown in the accompanying woodcut, which is taken from a photograph, for which, as for that of Case I, I am indebted to Dr. Gowers. She cannot stand without help, and then, on closing her eyes, she reels.

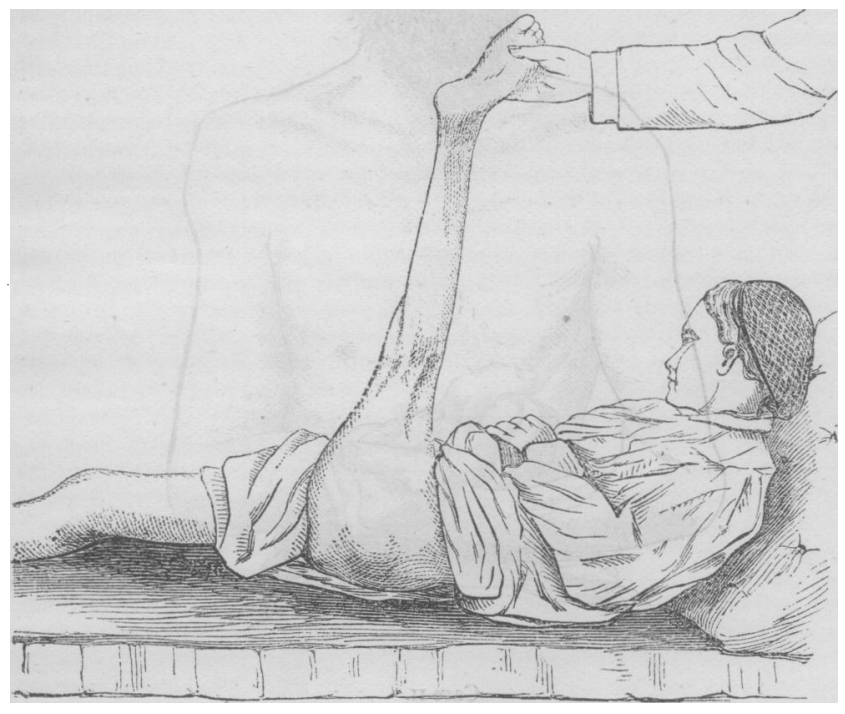

Case III.

The following case was under my care six years ago, affected with tabes and exhibiting joint affection with gastric crises.

CASE IV.- - John C., aged 43, a butler, had suffered for five years from shooting pains, chiefly in the calves, occurring at intervals of from six to eight days, and lasting several hours. When he applied at the hospital in February 1875 , the pains had gradually become much less severe and frequent. There was divergence of the optic axes. His pupils were contracted; his gait was ataxic, and he could not stand in the dark with his eyes shut. There was occasional leakage of the bladder. He described having had violent attacks of vomiting, occurring perhaps two or three times a year, and lasting a day or two. But besides this, he had had a gnawing and sinking sensation at the pit of the stomach almost daily, with a sickness and aversion from food. This was especially as regards anything which required mastication. $\mathrm{He}$ also complained of a frequent feeling as though he wanted to evacuate his bowels. Sometimes, he said, he felt as though there were a cannon-ball in his stomach. I found both his knee-joints much enlarged, and he told me that they had been twice as big. A month later his right knee-joint had still further enlarged, and evidently contained fluid. Not long after this I lost sight of the patient.

As I mentioned in my former paper, the expectations which were at first formed by Charcot, that the cause of these lesions of bones and joints would be discovered in atrophy of the anterior cornua of the spinal cord, have not been realised. The idea was founded upon the fact that in these cases there was usually more or less coincident muscular wasting. But in three recent necropsies (according to Talamon, Revue Mensuelle, I878, vol. ii) no muscular atrophy existed, and the anterior cornua were normal. On the other hand, I may remark that cases of advanced progressive muscular atrophy are of not uncommon occurrence, in which microscopical examination shows extensive destruction of cells in the anterior cornua, and in which there have been during life no changes whatever in the joints or bones. It is true, that this is not quite without exception. I have met with one case, a female, suffering from protopathic amyotrophy, in whom the finger-joints and elbows were the seat of marked changes. But these changes were precisely of the kind which is met with in arthritis defomans, and were very distinct from those characteristic of tabes. So, also, it is true that perhaps more often than not, in infantile paralysis, not only are the constituent parts of a joint relaxed so that the limb dangles, but the bones of the affected extremity cease to grow, and more or less deformity occurs. But here, again, the pathological condition is widely different from that which obtains in tabes. Spontaneous fracture, again, forms no part of the history of infantile paralysis, nor of progressive muscular atrophy; and in neither of these diseases do we ever see sudden painless and enormous swelling, involving not only the joint, but the whole extremity, followed by a rapid disappearance by absorption of an entire epiphysis and of bone beyond it, such as occurred in two of the cases related. No doubt the partial check to the growth of bones which occurs in infantile paralysis shows that the integrity of the anterior cornua is in some way necessary for the due development of osseous tissue; whether directly or indirectly, is another question. But in the arthropathy of tabes there would seem to be a destructive process at work different from any seen in other conditions, and implying, therefore, lesion of some portion of the nervous centres distinct from the anterior cornua of the cord, the effects of lesions of which are well recognised.

In one of the female patients, M., whom I showed at the Pathological Society, the two knee-joints were so hopelessly disorganised, that the patient had to use crutches, and to make great exertions with her arms, as she could not support herself on her legs. As a result, the muscles of her arms were developed like those of a labourer. Yet it was one of her shoulder-joints, bordered by these large muscles, which had begun to show signs of the same kind of affection as that in her knees. There had been great effusion, both in the joint and under the muscles of the shoulder and arm down to the elbow, and there was crepitation on movement. Such an association of muscular hypertrophy with jointaffection appears to be absolutely conclusive against disease of the anterior cornua being the cause of the latter. In the three cases of which I have to-day presented notes, I carefully tested electrically the muscles in the neighbourhood of the affected joint. In the case of P., whose left knee-joint was the seat of disease, the vastus internus muscle of that thigh responded to the lowest strength of induced current, which caused contraction in the corresponding muscle in the right limb. In Matilda H., whose left hip-joint is the seat of change, the muscles of the thigh respond to a normal strength of induced currentto the same strength as causes contraction in those of the right thigh. In the case of Henry $H$. alone, I found a slight reduction of faradaic excitability in the deltoid of the affected shoulder. This muscle was wanting in thickness, and was flabby. It had been exposed to a good deal of pressure from the large quantity of fluid which had occupied the joint, but which had recenlly greatly decreased, and it was disused. In the circumstances, I think this was sufficient to explain the slight diminution of excitability. In the case of S., whose left knee-joint was disorganised (Lancet, 1874), I found the muscles of the affected thigh actually more excitable to faradaism than those of the opposite side.

This preservation of faradaic excitability in muscles in the neighbourhood of disorganised joints affords manifestly a strong presumption against the view that disease of the anterior cornua is the cause of the arthropathy and absorption of bone. The fact, too, that my patient $W$., whose right hip-joint was completely disorganised (the head and neck of the femur being absorbed), was still able to walk some miles without crutches bears strongly in the same direction.

With still less probability can we attribute the cause of the affection of bones and joints to the disease of the posterior roots of spinal nerves, which is the essential lesion in tabes. For it is notorious that the most extensive changes in the posterior root-zones are perfectly compatible with complete preservation of the integrity of the joints. These peculiar affections of joints and bones only occur in a very moderate percentage of cases of tabes.* Moreover, although it is certainly common for the patient to have suffered severely from lightning-pains in the limb which afterwards becomes the seat of arthropathy, this is not universally the case, as it would probably be were the joint-affection connected with the disease of the posterior root-fibres. I questioned Matilda $\mathrm{H}$. very carefully upon this point, and she told me distinctly that, although she had suffered severely from shooting-pains about the malleoli, legs, and popliteal spaces, she had never had pains in either of her hip-joints. So,

* It is impossible to say what the percentage really is. In conversation upon the subject with Professor Charcot, a year or two ago, I told him that we rarely met with cases of tabetic arthropathy in England. He said: "You will find them in the workhouse infirmaries and in the surgical wards of hospitals." He was right. Two of my cases I discovered in workhouse infirmaries. Another was very nearly having the operation of excision of the knee-joint performed in a surgical ward of a hospital; two others, who had been inmates of surgical wards, had each been exhibited to candidates for a diploma at one of the examining boards as examples of rheumatoid arthritis. It is not, therefore, in the medical wards of hospitals, nor at a special hospital for paralysis, that one is likely to find many examples of these conditions. In most of those which I have published, the nature of the underlying disease had never been suspected. 
again, P., whose lightning-pains had affected both knees and ankles, had not suffered more in the left than the right knee; and for a year before any signs of mischief presented themselves in the knee-joint he had experienced much less of the pains than before. On the other hand, Henry $\mathrm{H}$. told me that the pains had been exceedingly severe in the left shoulder-joint, which was the seat of the changes. Another of my patients also (Worcester) described the occurrence of an unusually severe shock of pain in the affected limb immediately before the jointchanges began.

Now the gastric crises appear strongly to point to irritation of the roots of the vagus nerve in the medulla oblongata. The character of the retching, vomiting, and pain resembles remarkably that of the sym. ptoms of this class which I have seen to occur in hydrophobia. In that disease (as far as it is possible to prove it), as we know by the microscopical observations of Coacs and Gowers, vascular changes are often found affecting the pneumogastric nuclei. The lightning-pains of tabes, which depend upon irritative lesions of the posterior root-zones of the cord, are paroxysmal in character. We cannot explain the reason of this. All we know is, that they tend, after a few hours, days, or weeks, to pass off, and leave the patient absolutely free till another attack occurs. The crises gastriques are ordinarily characterised by a precisely similar tendency, and we have only to imagine the inflammatory changes of the posterior root-zones of the cord extending upwards into the medulla oblongata, and irritating the roots of the vagi, to see a complete explanation of the peculiarities of the gastric crises. Such an invasion of the roots of the vagi has not, so far as I know, been demonstrated; indeed, it has probably never been looked for. It is not easy to see any other reasonable explanation of the mode of origin of the gastric crises.

Supposing, then, that this be the cause, I suggest that the frequency of the coincidence of gastric crises with the osseous lesions gives reasonable ground for the hypothesis that the latter may depend upon an invasion of a part of the medulla oblongata closely adjacent to the roots of the vagi. It is only as a working hypothesis that I make the suggestion. Is there something which we may call provisionally a trophic centre for the osseous and articulatory system in the immediate neighbourhood of the roots of the vagi?

As I have suggested on a previous occasion, the discovery of such a centre would materially help us to explain the remarkable association of cardiac complications with the joint-affection of acute rheumatism, as well as the sweating characteristic of this disease, and the occasional hyperpyrexia which occurs in it. And it might also help to throw light upon the obscure pathology of arthritis deformans.

\section{ON THE USE OF OPTOMETERS FOR THE EX- AMINATION OF SOLDIERS AND WORKMEN EMPLOYED ON THE RAILROAD.}

By E. WARLOMONT, M.D., Brussels.

\section{I.-SOLDIERS.}

I. In order that a man may be fitted to discharge all the duties inherent to the profession of a soldier, he must possess certain physical qualities. For example, as regards the faculty of sight, he must at least be able to distinguish at a distance a battalion of infantry from a troop of cavalry; to occupy the position of patrol, vedette, or scout; to penetrate through a fog or through the darkness of the night, etc. For these purposes, his degree of visual acuteness must be at least a third in proportion to his normal acuteness, and his refraction must not exceed five diopters of myopia (one-seventh of the old reckoning) in the right eye, the accommodation being paralysed, or six diopters of hypermetropia (one-sixth of the old reckoning), apart from all element of accommodation by the use of mydriatics.

These are the limits prescribed by the ophthalmological department of the Medical Congress of Brussels in $1875,{ }^{*}$ in armies where the use of spectacles is permitted. In other cases, the degree of myopia must not exceed three diopters (one-twelfth to one-thirteenth of the old reckoning); and, in the case of hypermetropia, six metrical diopters. The Congress of I875 went no further; it committed to future Congresses the task of giving an opinion on the formation of committees of medical examination, and the manner in which they were to exercise their functions.

Since 1875, this question has made a step in advance; the use of spectacles has been authorised in several countries, and amongst others in Belgium, and the result of investigation appears to have been in

* With the exception of a very small fraction, the Congress of Brussels admitted, as a rule, provisionally, an acuteness varying from one-fourth to two-fifths. favour of the extension of instrumental means for determining ametropic defects and those of visual acuteness. Was this extension to be desired? and is the preference given to optical instruments over direct observation to be approved? In a scientific point of view, the answer would certainly be in the negative; in a practical sense (considering that the persons appointed to examine these questions are often wanting in sufficient experience to fit them for being accredited organs of objective science), the opposite conclusion may be formed. It may be objected, perhaps, that optometers are passive instruments, from which no absolute judgment can be obtained; but it must be borne in mind that the mathematical precision indispensable in scientific laboratories is not of such great importance in the councils of conscription, in which an approximate calculation, by means of a good optometer, will be sufficient. One thing is certain : the use of the optometer has found favour in several countries, Belgium included, where it has been adopted by the Government for the examination of volunteers, conscripts, and their substitutes. In accordance with a proposition made by a commission over which I had the honour to preside, this Government has adopted the Loiseau optometer (special model). This instrument, adapted to special and limited purposes, is the same we presented to the Academy of Medicine in Belgium, in the name of the inventor, in the meeting of the 25th January, 1879 (see Annals of Ophthalmology, January, February, 1879, page 40), but simplified by him, on account of the limited degree of services required in the commissions of conscription and medical examination.

The instrument consists of a single copper tube, three centimètres and a half in diameter, and eleven centimètres long (Fig. I), having at its

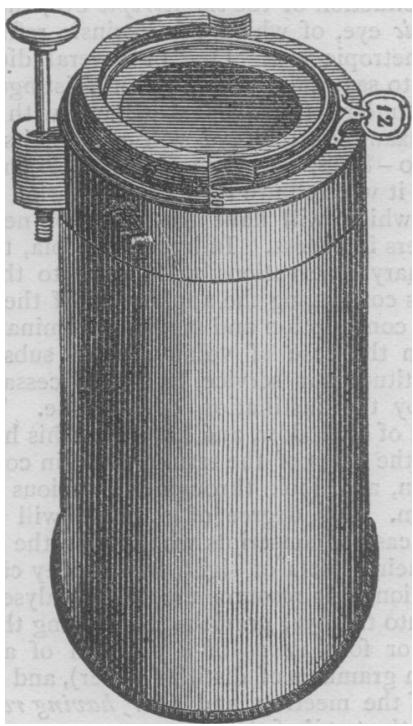

Fig. I.

front end a spring catch for the introduction of the lens, and a rod terminated by a blunt knob, which, coming into contact with the inferior orbital region, fixes the position of the eye observed at thirteen millie

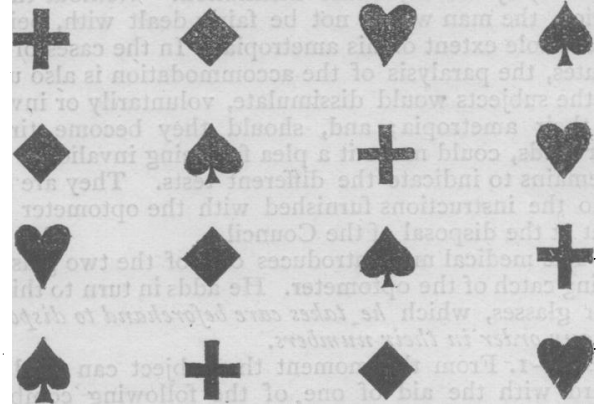

Fig. 2.

mètres from the lens. At one centimètre from the other extremity of the tube-viz., ten centimetres distant from the lens-is a board or 